\title{
William H. Arnold: In Memoriam
}

\author{
Harry Levinson \\ Editor-in-Chief
}

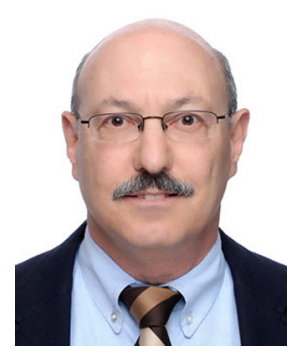

At the end of last year, the lithography and SPIE communities lost a good friend, Bill Arnold, who passed away on 27 December 2020.

He published under the name "William H. Arnold" but was known to everyone less formally as Bill. Although a person of considerable stature in our industry, he was always ready to help others become better technologists, and he was well-known for treating everyone with respect.

Bill joined SPIE in 1983, and in that same year he presented his first lithography-conference paper, "Image placement differences between 1:1 projection aligners and 10:1 reduction wafer steppers." In this paper are found a number of things that we now consider common knowledge among lithographers, such as non-linear overlay models, mix-and-match between dissimilar exposure tools, and the use of a stepper as a metrology tool, but these concepts were very novel in 1983. Bill went on to author or co-author a number of seminal papers. For example, his paper, "Overlay simulator for wafer steppers," presented at SPIE's Advanced Lithography Symposium in 1988, changed how lithographers looked at the statistics of overlay distributions. His papers on mask usage resulted in a completely new understanding of the number of wafers exposed per mask. This significantly influenced decisions made by the semiconductor industry regarding adoption of next-generation lithographic technologies, for which the mask was often an important consideration.

In early 1998, Bill joined ASML as their chief scientist, where he contributed to their success by bringing the perspective of a chip-maker to an equipment company. Bill's influence can be seen in ASML's holistic approach to lithography, which reflects that of practicing lithographers in wafer fabs.

Beyond his technical work, Bill often served on industry committees (which he often chaired), such as the technology working group that established the industry's first lithography roadmap. Other participants recall that Bill helped to guide these committees, often composed of people from rival companies, to consensus. Bill was able to be influential by calmly presenting even-handed, data-based, and well-reasoned arguments. He was known for seeing the bigger picture, which often included economic as well as technical considerations.

Bill was one of the first lithographers to be engaged with SPIE beyond the Advanced Lithography Symposium. For example, he served on the SPIE Publications Committee from 2001 to 2009 and chaired that committee for several of those years. Bill was a senior editor of this journal since its inception. He was also one of the first lithographers to become an SPIE Fellow (in 2004). Quite notably, he served as the president of SPIE in 2013.

I would like to exercise the editor-in-chief's prerogative and end on a personal note. Bill Arnold was already working at AMD when I joined that company in 1982. One of the first things that Bill did was to give me all of the articles on lithography that he had accumulated to that point. This enabled me to learn lithography quickly, while obviating many hours searching for this information (in those pre-Google times). I don't think that it occurred to Bill for even an instant that he might be helping a potential rival; that just wasn't the way that Bill thought. His approach resulted in many productive collaborations.

Bill Arnold was a good colleague and friend of many people in the lithography and SPIE communities, and he will be remembered well.

(C) 2021 Society of Photo-Optical Instrumentation Engineers (SPIE) 